PNL-3276

UC-60

\title{
Simulation of Atmospheric Turbulence
}

W. C. Cliff

D. L. Hall

January 1980

Prepared for the U.S. Department of Energy under Contract EY-76-C-06-1830

Pacific Northwest Laboratory Operated for the U.S. Department of Energy by Battelle Memorial Institute 
NOTICE

This report was prepared as an account of work sponsored by the United States Government. Neither the United States nor the Department of Energy, nor any of their employees, nor any of their contractors, subcontractors, or their employees, makes any warranty, express or implied, or assumes any legal liability or responsibility for the accuracy, completeness or usefulness of any information, apparatus, product or process disclosed, or represents that its use would not infringe privately owned rights.

The views, opinions and conclusions contained in this report are those of the contractor and do not necessarily represent those of the United States Government or the United States Department of Energy.

\author{
PACIFIC NORTHWEST LABORATORY \\ operated by \\ BATTELLE \\ for the \\ UNITED STATES DEPARTMENT OF ENERGY \\ Under Contract EY-76-C-06-1830
}

\author{
Printed in the United States of America \\ Available from \\ National Technical Information Service \\ United States Department of Commerce \\ 5285 Port Royal Road \\ Springfield, Virginia 22151
}

Price: Printed Copy $\$ \_$_ ; Microfiche $\$ 3.00$

NTIS

- Pages Selling Price

$\quad 001-025 \quad \$ 4.00$

026-050 \$4.50

$051-075 \quad \$ 5.25$

076-100 \$6.00

101-125 \$6.50

126-150 \$7.25

$151-175 \quad \$ 8.00$

$176-200 \quad \$ 9.00$

$201-225 \quad \$ 9.25$

$226-250 \quad \$ 9.50$

251-275 $\$ 10.75$

276-300 $\$ 11.00$ 
PNL-3276

UC-60

\section{3}

SIMULATION OF ATMOSPHERIC TURBULENCE

W. C. Cliff

D. L. Hall

January 1980

Prepared for

the U.S. Department of Energy under Contract EY-76-C-06-1830

Pacific Northwest Laboratory

Richland, Washington 99352 



\section{ACKNOWLEDGMENTS}

The authors are indebted to Dr. Jim Connell and the U.S. Department of Energy for support of this project and to Dr. C. E. Elderkin for discussions and comments on the basic approach. 
$\cdot$ 
This paper develops a method for constructing an artificial temporal sequence of velocity values for simulating atmospheric turbulence. The method develops the conditional probability density distribution of velocity given that the previous value of velocity is known. A value is randomly selected from the conditional probability density which then serves as a known value for the next conditional probability density function. Continuing this procedure provides the desired simulated sequence of velocity values.

Based upon this simulation method a program is developed for the Hewlett-Packard HP-29C (a) hand-held calculator for simulating the longitudinal component of atmospheric turbulence during neutral or strong wind conditions. The program takes 88 steps, and the only required inputs are the mean wind speed, the height above grade to be simulated, the local surface roughness, and the time desired between successive velocity values. The computer code may be easily modified for use on other comparable hand-held calculators and can obviously be modified for use on normal computing facilities.

(a) A specific product is used for example only; its use does not constitute an endorsement of the product. 
TABLE OF CONTENTS

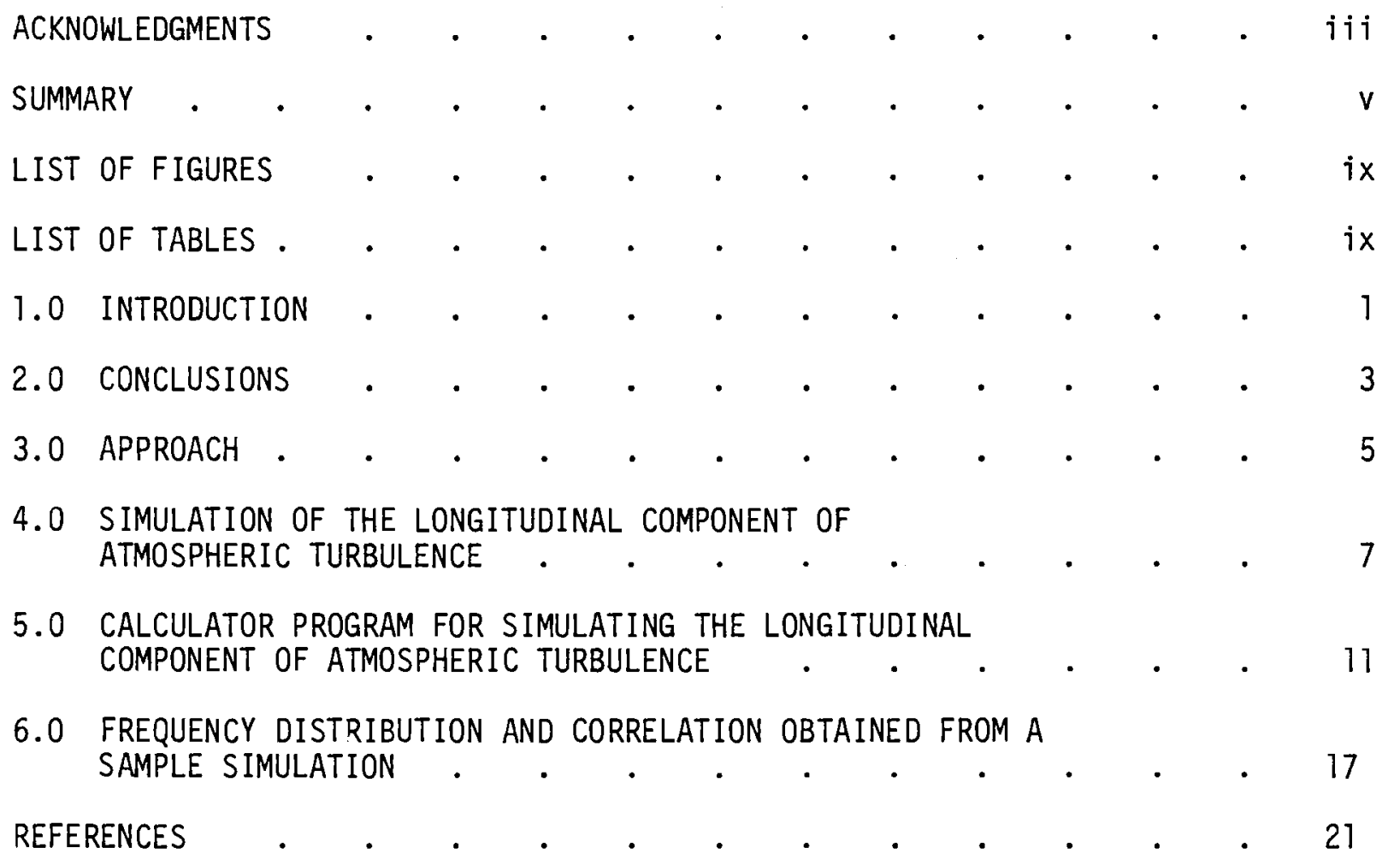


. 


\section{LIST OF FIGURES}

6.1 Frequency Distributions from Example Simulation and Theory, Norma 1 Distribution.

6.2 Autocorrelation Functions for Example Simulation and Theory (Negative Exponential) .

\section{LIST OF TABLES}

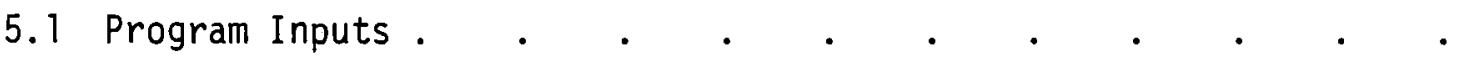

5.2 Code for Simulation of Longitudinal Component of Turbulence for the HP-29C Hand Calculator . . . . . . 12

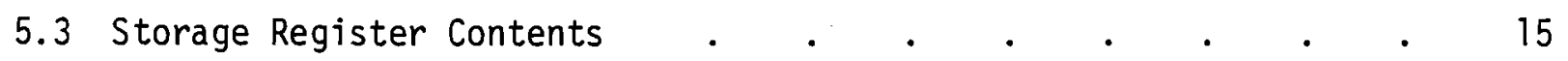

6.1 Frequency Distributions from Simulation and Theory . . . . 18

6.2 Autocorrelation Functions Derived from Simulated Wind History and Theory . . . . . . . . . . 
. 


\subsection{INTRODUCTION}

A knowledge of the interaction of turbulence with man-made structures such as wind turbines, airplanes, submarines, buildings, bridges, and power lines is essential to predict the structures' behavior and to provide the necessary criteria for adequate design. Since it is virtually impossible to provide measured records of turbulence for all conditions that a structure will encounter, methods to simulate turbulence under various conditions have been developed. $(1,2,3)$ Fichtl et al. ${ }^{(2)}$ provides excellent coverage of current turbulence simulation concepts and references.

The method developed in this paper uses the autocorrelation function and the conditional probability distribution of velocity given the preceding observation to simulate a time sequence of wind velocities. Most previous techniques have used the spectrum of turbulence for simulating velocity histories by appropriately filtering white noise to obtain the desired spectral characteristics. These methods require a greater number of steps than does the method presented in this paper.

For the special case of the longitudinal component of atmospheric turbulence a simple simulation program is developed that can be programmed on many available hand-held calculators. The simulation assumes that the turbulence is normally distributed and has the classical negative exponential autocorrelation. A negative exponential autocorrelation function has the property that if sample points separated by time $\tau$ have a correlation value of $\rho(\tau)$, then the correlation between points separated by time $n \tau$ is $(\rho(\tau))^{n}$. A specific program that provides the simulation will be presented after development of the method.

It should be noted that this method does not depend on the assumptions of normality or on the assumption of a negative exponential autocorrelation, and can be used to simulate histories with other, more complex, autocorrelation structures and with other density functions. 


\subsection{CONCLUSIONS}

A program for simulating atmospheric turbulence whose probability density function is Gaussian is developed for use on the Hewlett-Packard HP-29C hand calculator. This program takes 88 steps and requires as input the mean wind speed, the height at which the simulation is to be made, the local surface roughness, and the time between sequential velocity samples. The simulation method may be used to generate a single velocity history at a point. The simulation method may also be used to generate a velocity history at another location coincident in time with the wind history at a given location (which may have been generated by the simulation method itself). 


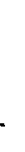




\subsection{APPROACH}

The basic approach to providing a method for simulating turbulence is to develop the conditional probability distribution of velocity, given that other velocities have been observed. Once the conditional distribution function is established, a value is selected from this distribution. This random value then becomes the desired simulated velocity, which in turn is used in selecting the next velocity value.

The conditional probability for the velocity at time $t+\tau$, given other velocities observed at previous times, is expressed as

$$
\begin{gathered}
P(V(t+\tau) \mid V(t), V(t-\tau) \ldots, V(t-n \tau))= \\
\frac{P(V(t+\tau), V(t) \ldots, V(t-n \tau))}{P(V(t), \ldots V(t-n \tau))} .
\end{gathered}
$$

The conditional density function of $V(t+\tau)$ given previous velocities, is given by

$$
\begin{aligned}
& f(V(t+\tau) \mid V(t), \ldots V(t-n \tau))= \\
& \frac{f(V(t+\tau), V(t), \ldots, V(t-n \tau))}{f(V(t), V(t-\tau) \ldots V(t-n \tau))}
\end{aligned}
$$

Thus, to establish the conditional density function one is required to know the full joint density function and the joint density function of the given variables. Once these are established, the simulation of turbulence is initiated by assuming (or obtaining by other means) nominal values for $V(t), V(t-\tau) \ldots V(t-n \tau)$ and randomly selecting a value of $V(t+\tau)$ from the conditional density function for $V(t+\tau)$.

A suggested method for simulating turbulence in both space and time is to first simulate in time a given location and then use that time history for simulating the time history at a location spatially separated from the first location. 


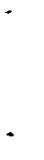




\subsection{SIMULATION OF THE LONGITUDINAL COMPONENT OF ATMOSPHERIC TURBULENCE}

The longitudinal component of atmospheric turbulence may be simulated using the conditional probability method by using the standard assumptions that the turbulence is normally distributed and that the autocorrelation has the form of a negative exponential. Since the autocorrelation is assumed to have the form of a negative exponential, $V(t+\tau)$ depends only on the previous velocity $V(t)$ and on no other velocities. ${ }^{(4)}$ Thus, only $f(V(t+\tau) \mid V(t))$ need to be considered.

The conditional probability density function of the longitudinal velocity at time $t+\tau, V(t+\tau)$, given the velocity at time $t, V(t)$, becomes

$$
f(V(t+\tau) \mid V(t))=\frac{1}{\sigma \sqrt{1-\rho^{2}}} \phi\left(\frac{V(t+\tau)-\bar{V}-\rho(V(t)-\bar{V})}{\sigma \sqrt{1-\rho^{2}}}\right)
$$

$$
\text { where } \phi(x)=\frac{1}{\sqrt{2 \pi}} e^{-\frac{x^{2}}{2}}
$$$$
\rho=\text { correlation coefficient between } V(t+\tau) \text { and } V(t)
$$$$
\bar{V}=\text { mean velocity }
$$$$
\sigma=\text { the standard deviation of velocity (rms). }
$$

A11 quantities except $V(t+\tau)$ in equation 3 may be solved for as follows:

$\bar{V}=$ mean wind velocity at the height at which the simulation is to be performed. This value is selected as desired ( $\bar{V}$ in meters/second).

$\tau=$ time between successive velocity samples. This value is selected as desired. That is, if one wants one second spacing between observations of velocity, $\tau$ is set at one second ( $\tau$ in seconds).

$\rho=$ correlation coefficient between velocity samples spaced $\tau$ seconds apart. $\rho$ may be computed from: 


$$
\rho=e^{-\frac{\bar{V} \tau}{L}}
$$

where

$$
L=25 z_{0}^{-0.4} z^{c}(L \text { in meters) }
$$

and

$$
C=\operatorname{Exp}\left(-0.025\left(\ln z_{0}\right)^{2}+0.17 \ln z_{0}-0.8\right)
$$

$$
Z=\text { height }(\mathrm{agl}) \text { at which simulation is being performed }
$$
( $Z$ in meters)

$$
\begin{aligned}
z_{0} & =10 c a l \text { surface roughness } \\
z_{0} & =0.005 \mathrm{~m} \text { smooth surface } \\
& =0.05 \mathrm{~m} \text { moderate terrain } \\
& =0.5 \mathrm{~m} \text { rough terrain }
\end{aligned}
$$

The above representation for $L$ is consistent with Reference 5 .

A somewhat simpler but more conservative formula for $L$ is used in this study's code development: ${ }^{(6)}$

$$
\begin{aligned}
& L=25 z^{0.35} z_{0}^{-0.063} \quad(L \text { in meters) } \\
& \sigma=\text { the standard deviation of wind speed (rms) that may be } \\
& \text { computed from } \\
& \sigma=\frac{\bar{V}}{\ln \left(\mathrm{Z} / \mathrm{Z}_{0}\right)}(\text { ref. } 7)
\end{aligned}
$$

The next step in the simulation is to develop a method of selecting a random number from a normal frequency distribution that has zero mean and unit variance. This is accomplished by selecting two random numbers, $U_{i}$ and $U_{j}$, from uniform distributions and performing the following operation that results in a random variable, $N_{i}$, whose frequency distribution is Gaussian. (8) 


$$
N_{i}=\left(-2 \ln U_{i}\right)^{1 / 2} \cos \left(2 \pi U_{j}\right)
$$

Each successive, $N_{i}$, is used in the following equation to compute a new longitudinal wind velocity, $v_{i}$.

$$
v_{i}=\sigma \sqrt{1-\rho^{2}} N_{i}+\bar{V}(1-\rho)+\rho V_{i-1}
$$

where $V_{i-1}$ is the previous velocity obtained in the simulation.

To start a simulation the investigator may use any initial velocity desired, including the hourly mean value. Any standard random number generation scheme may be used to obtain the required $U_{i}$ and are $U_{j}$ values.

A calculator program, based upon Equation 11 , for simulating the longitudinal component is presented in the following section. 


\subsection{CALCULATOR PROGRAM FOR SIMULATING THE LONGITUDINAL COMPONENT OF ATMOSPHERIC TURBULENCE}

This section contains a listing of a program to simulate the longitudinal component of turbulence. The required input information is listed in Table 5.1. The user enters these inputs by storing the values in the identified registers.

TABLE 5.1. Program Inputs

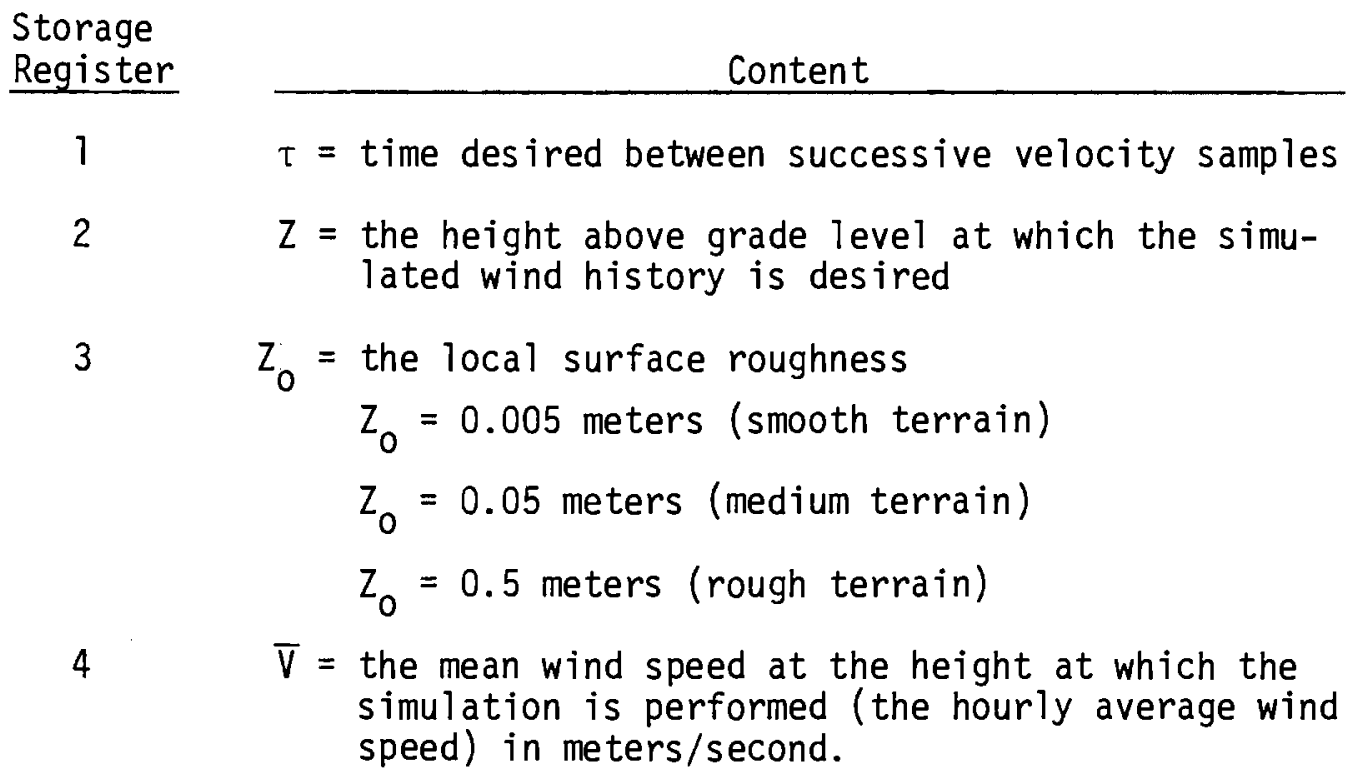

To run the program the operator presses GSB-1 for the first value of wind speed, then presses $R / S$ for each successive value.

The program is listed in Table 5.2; the storage registers used by the program are listed in Table 5.3. 
TABLE 5.2. Code for Simulation of Longitudinal Component of Turbulence for the HP-29C Hand Calculator

\begin{tabular}{|c|c|c|c|c|}
\hline Step & \multicolumn{4}{|c|}{ Code } \\
\hline 1 & 15 & 13 & 017 & \\
\hline 2 & & 24 & 2 & \\
\hline 3 & & & 73 & \\
\hline 4 & & & 03 & \\
\hline 5 & & & 05 & \\
\hline 6 & & 14 & 64 & \\
\hline 7 & & & 02 & \\
\hline 8 & & & 05 & \\
\hline 9 & & & 61 & Computes Lu \\
\hline 10 & & 24 & 03 & \\
\hline 11 & & & 73 & \\
\hline 12 & & & 00 & \\
\hline 13 & & & 06 & \\
\hline 14 & & & 03 & \\
\hline 15 & & 14 & 64 & \\
\hline 16 & & & 71 & \\
\hline 17 & & 23 & 08 & \\
\hline 18 & & 15 & 74 & \\
\hline 19 & & 24 & 017 & \\
\hline 20 & & & 61 & \\
\hline 21 & & 24 & 04 & \\
\hline 22 & & 23 & 05 & Compute $\rho$ \\
\hline 23 & & & 61 & \\
\hline 24 & & & 32 & \\
\hline 25 & & 15 & 42 & \\
\hline 26 & & 23 & $.5]$ & \\
\hline 27 & & 15 & 637 & \\
\hline 28 & & & 32 & \\
\hline 29 & & & 01 & \\
\hline 30 & & & 51 & \\
\hline 31 & & 14 & 63 & \\
\hline
\end{tabular}


TABLE 5.2. (continued)

Step

32

33

34

35

36

37

38

39

40

41

42

43

44

45

46

47

48

49

50

51

52

53

54

55

56

57

58

59

60

61
Code

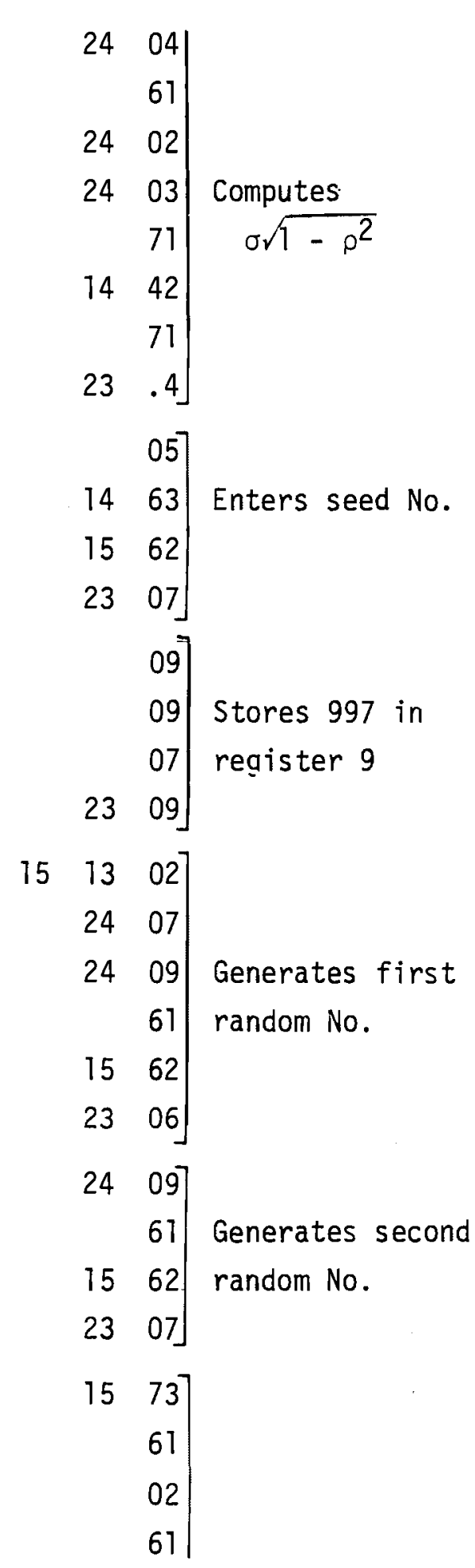


TABLE 5.2. (continued)

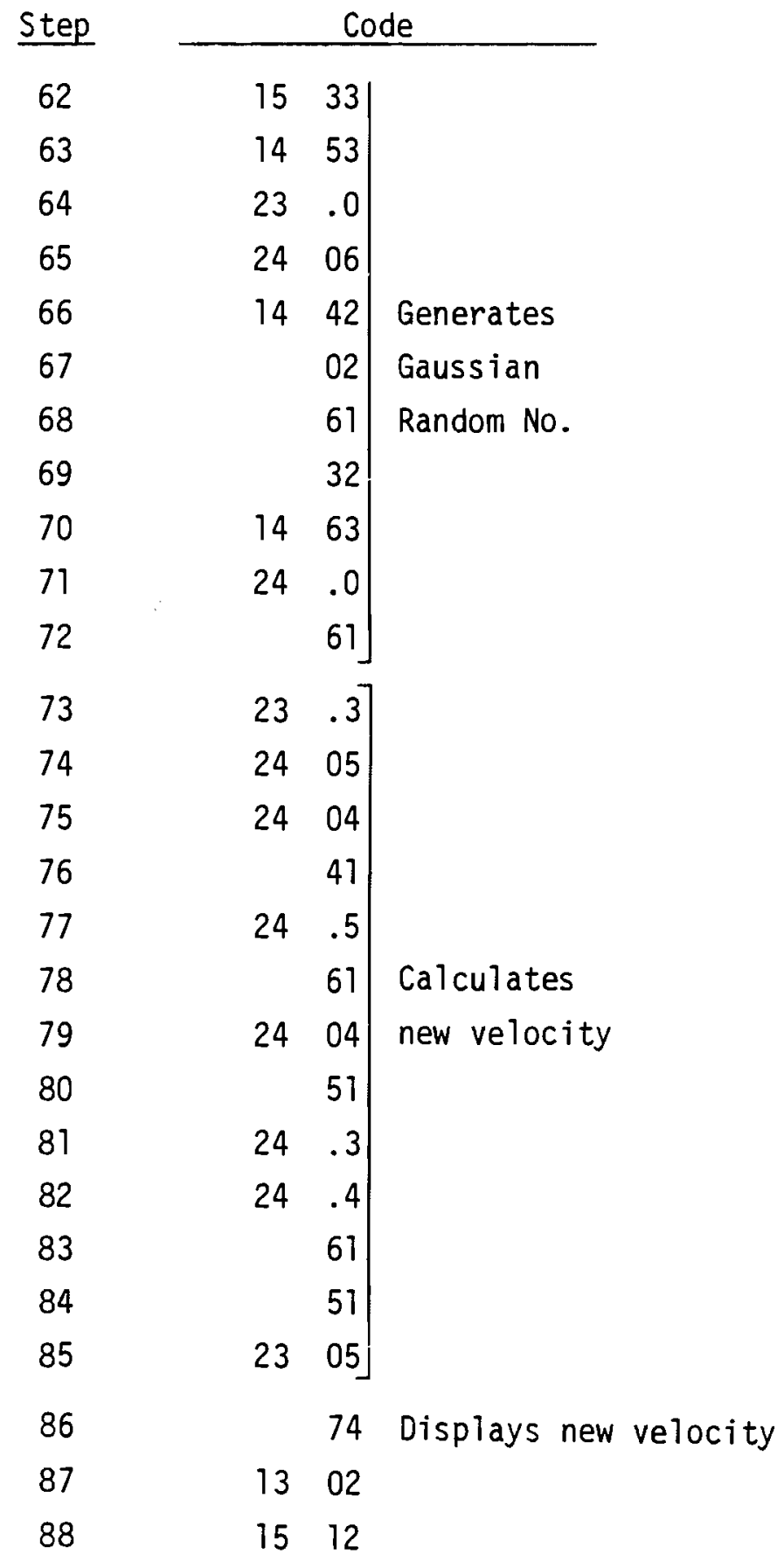


TABLE 5.3. Storage Register Contents (a)

Storage

Register

Contents

0

Not used

1 Time between samples (set prior to operation) $=\tau$ (second)

2 Height above ground for simulation $=z$ (meters)

3 Surface roughness for local topography $=z_{0}$ (meters)

4 Mean wind speed at height of simulation (meters/second)

5 Used internally (becomes $V_{t+\tau}$ )

6 Used internally to program (random no. 1, $U_{i}$ )

7 Used internally to program (random no. $2, U_{j}$ )

8 Used internally to program = Lu

9 Used internally to program

$.0 \quad$ Used internally to program

$.1 \quad$ Not used

$.2 \quad$ Not used

.3 Used internally to program $=\mathrm{N}_{i}$

$.4 \quad$ Used internally to program $=\bar{U} \sqrt{1-\rho^{2}} / \ln \left(z / z_{0}\right)$

$.5 \quad$ Used internally to program $=\rho$

(a) To run program press GSB-1 for first value; then press R/S for each successive value of wind speed. 


\subsection{FREQUENCY DISTRIBUTION AND CORRELATION OBTAINED FROM A SAMPLE SIMULATION}

The simulation code presented in the text was used to generate a typical simulation and the statistical distributions acquired from the simulation.

The required inputs to the program were:

$\tau=1$ second between samples

$Z=25$ meters $=$ height of simulated measurement

$Z_{0}=0.05$ meters (medium terrain)

$\bar{V}=10$ meters $/$ second $=$ mean wind speed

Ten thousand sample points were generated from which the following statistics were computed:

- frequency distribution of longitudinal wind speed

- Autocorrelation function of longitudinal wind speed

Table 6.1 lists the frequency distribution of longitudinal wind speed obtained from the values generated by the simulation program along with the expected values calculated from a normal distribution. Figure 6.1 is a plot of the generated frequency distribution and the corresponding normal distribution. The two curves are extremely close in magnitude except that the simulation gave a few more large excursions than would be expected from the normal distribution. This is somewhat helpful, however, in that larger than norma 1 excursions are expected in atmospheric turbulence. 
TABLE 6.1. Frequency Distributions from Simulation and Theory

\begin{tabular}{|c|c|c|}
\hline $\begin{array}{c}V \\
(\mathrm{~m} / \mathrm{s})\end{array}$ & $P\left(V_{\text {sim }}\right)$ & $\mathrm{P}(\mathrm{V})_{\text {normal }}$ \\
\hline 3 & 0.000 & 0.000 \\
\hline 4 & 0.000 & 0.000 \\
\hline 5 & 0.000 & 0.002 \\
\hline 6 & 0.008 & 0.010 \\
\hline 7 & 0.048 & 0.044 \\
\hline 8 & 0.121 & 0.115 \\
\hline 9 & 0.169 & 0.204 \\
\hline 10 & 0.242 & 0.248 \\
\hline 11 & 0.210 & 0.204 \\
\hline 12 & 0.139 & 0.115 \\
\hline 13 & 0.038 & 0.044 \\
\hline 14 & 0.018 & 0.011 \\
\hline 15 & 0.004 & 0.002 \\
\hline 16 & 0.001 & 0.000 \\
\hline 17 & 0.002 & 0.000 \\
\hline 18 & 0.000 & 0.000 \\
\hline 19 & 0.000 & 0.000 \\
\hline 20 & 0.000 & 0.000 \\
\hline
\end{tabular}

Table 6.2 gives the tabular values of the autocorrelation function obtained from the simulated wind history and the expected negative exponential autocorrelation function.

Figure 6.2 provides a comparison of the two correlations. The two correlations are in excellent agreement, indicating that the simulation develops realistic correlation and spectral information. 


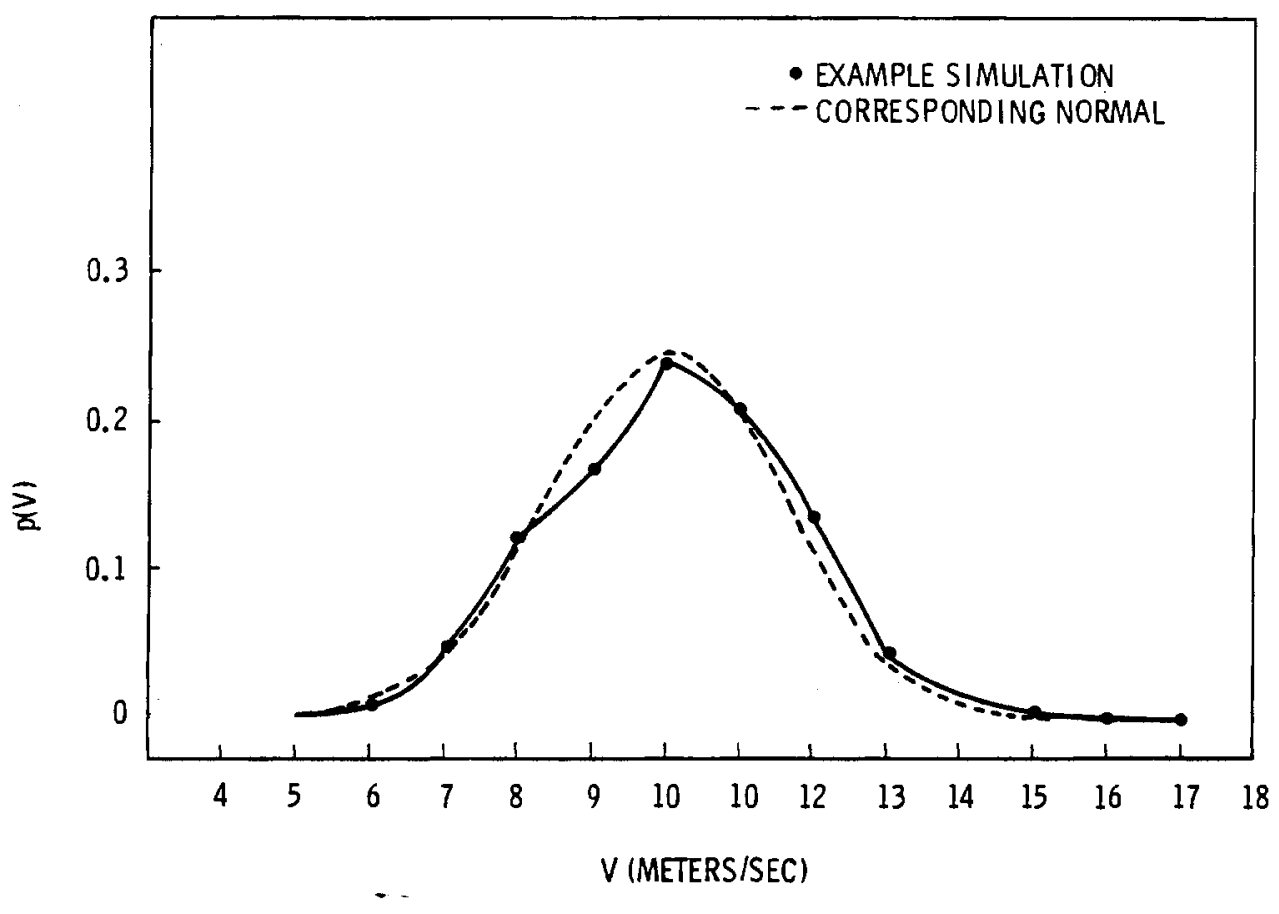

FIGURE 6.1. Frequency Distributions from Example Simulation and Theory, Normal Distribution

TABLE 6.2. Autocorrelation Functions Derived from Simulated Wind History and Theory

$\begin{array}{ccc}\text { Time Delay } & \begin{array}{c}\text { Autocorrelation } \\ \text { (Simulation) }\end{array} & \begin{array}{c}\text { Autocorrelation } \\ \text { (Expected) }\end{array} \\ 1 & 0.898 & 0.898 \\ 2 & 0.807 & 0.807 \\ 3 & 0.723 & 0.725 \\ 4 & 0.650 & 0.651 \\ 5 & 0.586 & 0.585 \\ 6 & 0.532 & 0.525 \\ 7 & 0.480 & 0.472 \\ 8 & 0.432 & 0.424 \\ 9 & 0.388 & 0.381 \\ 10 & 0.348 & 0.342 \\ 11 & 0.312 & 0.307 \\ 12 & 0.284 & 0.276 \\ 13 & 0.260 & 0.248 \\ 14 & 0.238 & 0.222 \\ 15 & 0.209 & 0.200 \\ 16 & 0.182 & 0.179 \\ 17 & 0.160 & 0.161 \\ 18 & 0.141 & 0.145 \\ 19 & 0.125 & 0.130 \\ 20 & 0.108 & 0.117\end{array}$




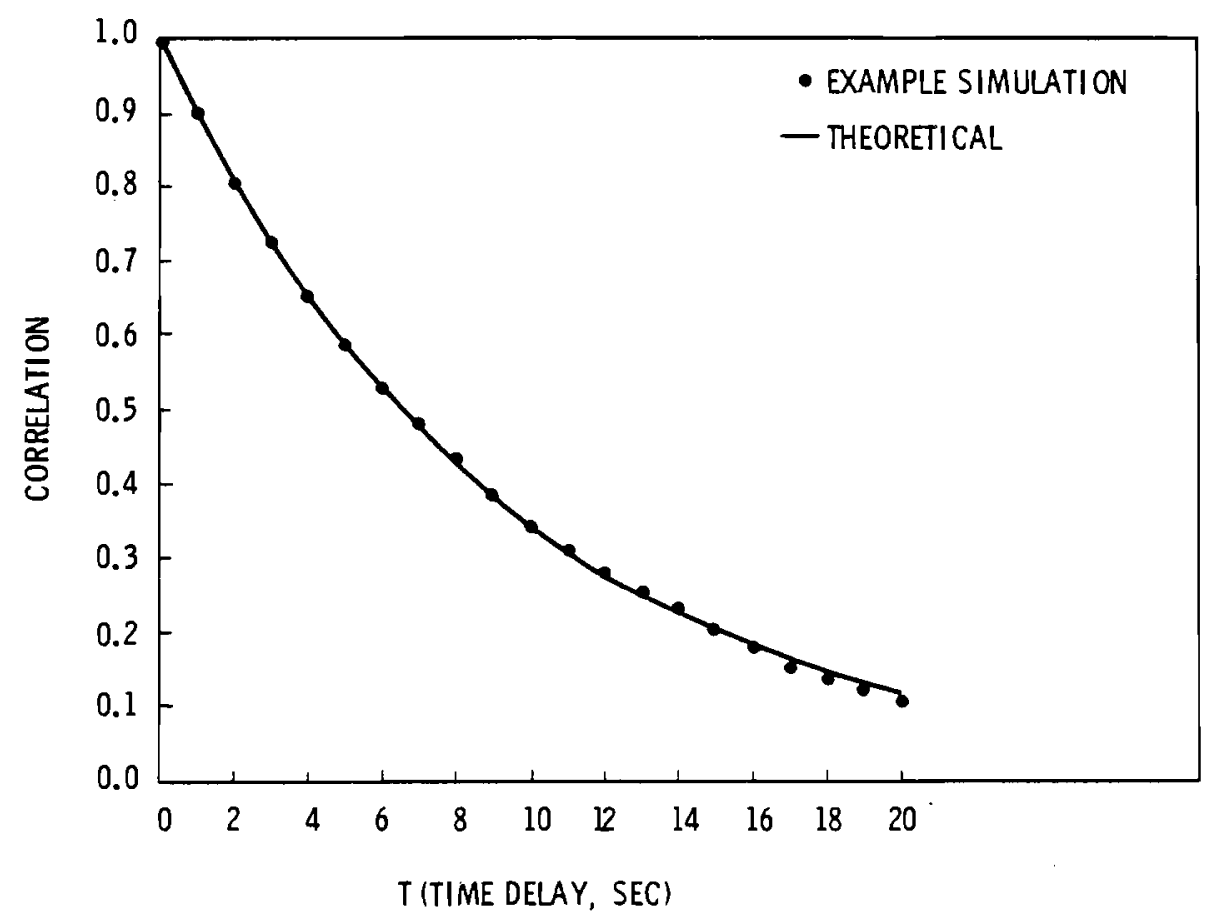

FIGURE 6.2. Autocorrelation Functions for Example Simulation and Theory (Negative Exponential) 


\section{REFERENCES}

1. G. H. Fichtl, M. Perlmutter and W. Frost, "Monte Carlo Turbulence Simulation, "Chapter 14 of Handbook of Turbulence. Vol 1, Plenum Press, New York, NY, 1977.

2. F. Neuman, J. D. Foster, Investigation of a Digital Automatic Aircraft Landing System in Turbulence. NASA TN D-6066, Washington, DC., October 1970.

3. G. H. Fichtl and M. Perlmutter, "Nonstationary Atmospheric Boundary Layer Turbulence Simulation," Paper no. 74-587, presented at AIAA Seventh Fluid and Plasma Dynamics Conference, 1974.

4. G. E. P. Box and G. M. Jenkins, Time Series Analysis. Holden-Day, San Francisco, CA, 1970.

5. J. Counihan, Adiabatic Atmospheric Boundary Layers, Atmospheric Environment. Vol. 9, pp. 871-905, Pergamon Press, 1975.

6. Characteristics of Atmospheric Turbulence Near the Ground, Part II: Single Point Data for Strong Winds (Neutral Atmosphere). Item No. 74031, Engineering Sciences Data Unit, London, October 1974.

7. W. C. Cliff, G. H. Fichtl, Wind Velocity-Change (Gust Rise) Criteria for Wind Turbine Design. PNL-2526, Pacific Northwest Laboratory, RichTand, WA, JuTy 1978.

8. M. Abramowitz and I. A. Stegum, eds. Handbook of Mathematical Functions. Nationa 7 Bureau of Standards, AMS-55, 1972. 

PNL-3276

UC-60

\section{DISTRIBUTION}

No. of

Copies

OFFSITE

A. A. Churm

DOE Chicago Patent Group

9800 S. Cass Avenue

Argonne, IL 60439

C. I. Aspliden

Department of Energy

600 E. Street, N.W.

Washington, DC 20545

G. P. Tennyson

Department of Energy

Albuquerque Operation Office

P.0. Box 5400

Albuquerque, NM 87115

27 DOE Technical Information Center

\section{ONSITE}

3 DOE Richland Operations Office

H. E. Ransom

R. K. Stewart

S. Smith
No. of

Copies

74 Pacific Northwest Laboratory

W. R. Barchet

J. R. Connel 1

W. C. Cliff (20)

J. C. Doran

R. L. Drake

C. E. Elderkin

D. L. Elliott

R. L. George

D. L. Hall

T. R. Hiester

R. L. Hooper

T. C. Jameson

W. W. Laity

A. H. Miller

P. R. Partch

W. T. Pennell

E. H. Phinney

D. C. Powe 11

J. V. Ramsde 11

D. S. Renne

H. L. Wegley

L. L. Wende 11

R. K. Woodruff

Technical Information - Library Publishing Coordination (2) 


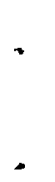

1 